\title{
The Integration of Dictionary Use Strategy Training into Basic English Class
}

\author{
Lin Liu \\ School of Foreign languages, University of Jinan, Jinan, China
}

\begin{abstract}
Based on the previous research which showed that students knew little about effective ways of dictionary consultation due to the lack of formal dictionary use training, the author worked out specific teaching contents and approaches on dictionary use strategy training, and systematically carried them out among 80 first-year English majors by integrating the training into their Basic English class. The follow-up interview showed that students' efficiency in using dictionaries and their independent language learning had been improved through the training.
\end{abstract}

Index Terms - dictionary use strategy, training, English majors, basic English

\section{INTRODUCTION}

Chinese Syllabus for College English Majors requires clearly that in terms of using reference books, freshmen and sophomores should "be skillful in using bilingual dictionaries and easy monolingual dictionaries", juniors and seniors should "be adept at using all kinds of monolingual dictionaries and large encyclopedias, be able to solve problems in both language and other fields".

However, our observation and previous research (Liu Lin, 2013) revealed that though teachers are aware of the importance of encouraging students to use dictionaries in English learning and have taken certain measures, they do not know exactly how to guide students to use dictionaries efficiently. Few teachers have systematically taught students to use dictionaries, or designed various exercises to train students' dictionary use strategies. Also, few teachers tell students the types of dictionaries and their usages appropriate at different learning phases and in different learning activities.

The lack of training and instruction resulted in a series of problems. Firstly, when buying dictionaries, faced with different kinds of dictionaries from different publishers, students do not know which one to choose. Secondly, though students have mastered some basic skills of consulting dictionaries, they are still confused about how to take advantage of dictionary use strategies for English learning. The problems are manifested as follows: 1) Students rely too much on mobile phone dictionaries or pocket e-dictionaries. 2) Students know little about high-quality pedagogical dictionaries, let alone monolingual dictionaries. 3) When looking up a word in a dictionary, students only read the first or the first few meanings, without paying attention to other meanings, illustrative sentences, or collocations. 4) After buying a dictionary, students rarely read the preface, guide to using the dictionary, style explanation, appendices and other required readings, thus resulting in the misuse of dictionary. Consequently, it is often the case that in reading, students do not know when to consult dictionaries or even though they have consulted the dictionary, they only apply the meanings mechanically; in translation, students often mistranslate words and phrases; in writing, they rely too much on sentence to sentence translation, with Chinglish emerging endlessly.

\section{LITERATURE REVIEW}

Researches on dictionary use mainly focused on three aspects: types of dictionaries used by language learners (Cubillo, 2002; Lang Jianguo\&Li Jin, 2003; Chen Yuzhen, 2007); the purposes of using dictionaries by language learners (Bejoint, 1981; Atkins \& Varantola, 1998; Shi Gengshan \& Chen Guohua, 2007); language learners' dictionary use strategies (Laufer \& Kimmel 1997; Zhao Wei, 2004; Meng Zhen \& Shao Chenghua, 2005; Chen Yuzhen, 2008).

Researchers abroad explored specific perspectives of dictionary use. For example, Huang Shufen and Zohreh Eslami (2013) discussed the use of dictionary and contextual guessing strategies for vocabulary learning by advanced English-language learners. Holi Ibrahim Holi Ali (2012) examined monolingual dictionary use in an EFL context.

Researchers in China found the urgency that students didn't have sufficient dictionary use strategies. They suggested that teachers should give expert guidance in students' dictionary use. For instance Chen Yuzhen (2008) proposed that training should be offered to teachers so that they can give effective guidance to students in dictionary use. Chen Min and Li Shoujing (2009) conducted a survey on first-year students' dictionary use in vocabulary learning, and found out that students' poor skills of using dictionary had a negative influence on their learning efficiency. They deemed it necessary to integrate the instruction of dictionary use into regular teaching, and teachers should have the awareness to provide guidance to develop students' dictionary use strategies.

However, most of the researches merely drew some conclusions from the survey on dictionary use and put forward 
some suggestions based on the discussion of the results. Only a few empirical researches explored how to practically cultivate students' dictionary use strategy in classroom teaching. A typical example is An Innovative Research on High School English Teaching Based on E-dictionary (Wang Qiang \& Chen Zehang, 2011) carried out by the Institute of Foreign Language Education and Teacher Education of Bei Jing Normal University from 2008 to 2009, which found that classroom training and instruction played a very important role in students' dictionary use strategies. But it is infeasible for all the students to have the same kind of advanced and expensive e-dictionary in English class unless being subsidized as what was done in that research. Li Hongna (2007) probes into the influence of dictionary use strategy training on students' vocabulary learning. But the research neglected the fact that dictionaries are not only used in learning vocabulary, but also in other aspects of language learning such as reading, translation and writing.

Since dictionaries are indispensable in all aspects of language learning, using dictionaries properly was regarded as one of the cognitive strategies (O'Malley \& Chamot, 1990), which also reflects students' autonomous learning ability. Therefore, it is necessary to introduce the instruction of dictionary use strategy in English major teaching so as to help learners solve many language problems by themselves.

However, with limited conditions, it is infeasible to offer professional dictionary use courses for freshmen. Henri Béjoint (1994) points out that the most efficient teaching method for dictionary users is to integrate dictionary use training into regular courses so as to get dictionary use teaching finished in classroom teaching system. As Basic English is a highly comprehensive course with many class hours and is set for lower grade students, it is appropriate to integrate dictionary use strategy training into the teaching of Basic English flexibly.

\section{Dictionary USE STRATEgy TRAINING}

\section{A. Subjects}

The subjects participated in the training were 80 first-year English majors who just completed their first semester's study.

\section{B. Teaching Principle}

The research plans to combine dictionary lectures with regular Basic English teaching and students' extra-class study. Tasks are designed in dictionary lectures to enhance students' efficiency of using dictionaries as well as raise students' awareness of using strategies. Meanwhile, students' dictionary using strategies are constantly practiced in regular Basic English class as well as extra-class study, which, in turn, reflects the problems and students' need in using dictionaries in English study, thus provide materials and basis for dictionary lectures. In regular Basic English class, teachers can encourage students' initiative by asking them to share their notes taken in their extra-class study. Through extra-class study, students can practice the dictionary using strategies, obtain more proficiency, and expand the knowledge learned in class. Figure 1 illustrates the interrelationship among dictionary lecture, regular Basic English class and extra-class study.

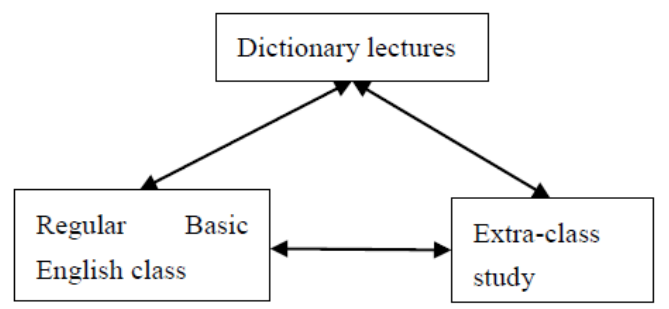

Figure 1. The interrelationship among dictionary lecture, regular Basic English class and extra-class study.

\section{Procedures}

Nine lectures concerning the using of dictionaries are given to the students during one semester.

Lecture 1: How to choose and use English dictionaries. This lecture includes the following five contents. 1) The definition of English learning dictionaries, their characteristics and good examples of learning dictionaries. 2) Definition and examples of bilingualized dictionaries as well as illustration of the advantages of binlingualized dictionaries over bilingual dictionaries. 3) Using different dictionaries to solve different problems (see Table 1). 4) Preface and user guide in dictionaries. 5) How to choose a dictionary. 
TABLE 1.

USING DIFFERENT DICTIONARIES TO SOLVE DIFFERENT PROBLEMS

\begin{tabular}{|l|l|l|}
\hline Types of dictionaries & Functions & Examples \\
\hline Monolingual dictionary & $\begin{array}{l}\text { 1. The exact meaning of an unknown word } \\
\text { 2. New meanings of a known word } \\
\text { 3. Slangs, colloquialism }\end{array}$ & $\begin{array}{l}\text { Macmillan English Dictionary For Advanced Learners of } \\
\text { American English } \text { (Foreign Language Teaching and } \\
\text { Research Press, 2003) }\end{array}$ \\
\hline English-Chinese dictionary & Difficult words, rarely used words & $\begin{array}{l}\text { A New English-Chinese Dictionary (Shanghai Translation } \\
\text { Publishing House, 2003) }\end{array}$ \\
\hline Bilingualized dictionary & Learning basic words & $\begin{array}{l}\text { Oxford Advanced Learner's English-Chinese Dictionary } \\
\text { (The Commercial Press / Oxford University Press, 2004) }\end{array}$ \\
\hline $\begin{array}{l}\text { Chinese-English dictionary } \\
\text { pocket e-dictionary / } \\
\text { mobile-phone dictionary }\end{array}$ & Chinese-English translation & $\begin{array}{l}\text { A Modern Chinese-English Dictionary (Foreign Language } \\
\text { Teaching and Research Press, 2001) }\end{array}$ \\
\hline
\end{tabular}

Lecture 2: Introduction to some commonly used English dictionaries. This lecture introduces seven types of dictionary in terms of their sizes, purposes, characteristics, functions, merits and demerits. The dictionaries introduced in this lecture include Longman Dictionary of Contemporary English (LDOCE), Oxford Advanced Learner's Dictionary of Current English (ALD), Collins Dictionary of the English Language (CDOEL), Webster's New World Dictionary of the American Language (WNWD), Dictionaries of idioms, Dictionaries of collocations, Dictionaries of synonyms and thesauri.

Lecture 3: Using monolingual dictionaries in English study. This lecture introduces some monolingual dictionaries such as Oxford Student's Dictionary of Current English, Oxford Advanced Learner's Dictionary of Current English, Penguin English Student's Dictionary, Concise Oxford Dictionary and Cambridge International Dictionary of English. Students are encouraged to choose proper dictionaries according to their different proficiency. Sufficient examples are offered to illustrate the functions of monolingual dictionaries: Students can be exposed to English by consulting monolingual dictionaries. They can learn to think in English and hence reduce the chance of making Chinglish. Properly choosing a monolingual dictionary and using it can help students to understand the exact meaning of words, and improve their English writing ability.

Lecture 4: Using dictionaries to gain improvement in reading and vocabulary.

Based on a passage, the teacher designed exercises and activities for students to grasp the main idea of the passage, guess the meanings of words according to their context, analyze word formation, and compare different words with the help of dictionary so as to get an idea of how to express views with proper words. In forms of independent learning, exploration and collaboration, students experienced how to guess meanings from contexts, how to clear away vocabulary obstacles in reading with the help of dictionaries. The purpose is to increase students' speed and raise their interest in reading, develop their ability to choose proper words in writing and cultivate their comprehensive ability in reading.

Lecture 5: Using dictionaries in translation from English into Chinese. Four steps are designed to help students make the best of dictionary in prose translation: 1) understand the prose; 2) find out difficult words; 3) try to translate the difficult words with the help of the Chinese-English Dictionary; 4) decide which English word or phrase should be used with the help of the English-English dictionary, English-Chinese Dictionary, the Collocation Dictionary, etc. Divide students into groups of four and ask them to appreciate and translate Sonnet 18 and A Red, Red Rose into Chinese through group discussion. Students participated actively in the activities, and produced fine translations. The reasons may be as follows: Firstly, students could understand the poems very well. Secondly, the topic of "love" is attractive to them. They like to discuss and experience the different ways of expressing love by ancient and contemparay poets. Thirdly, using dictionaries throughout the whole class made the previously boring and difficult appreciation for poems become active, relaxing and operational.

Lecture 6: Using dictionaries in translation from Chinese into English. Students work in groups of four to translate a selected part of the Chinese prose Moonlight over the Lotus Pond. They shall follow the same four steps in Lecture 5, get prepared for the presentation in which each group should show the class how they manage to translate it. They may need someone to write on the blackboard, someone to handle dictionaries and someone to give a short speech about their choice of words. The teacher gives necessary feedback and comment on their presentation.

For the students, translating proses or poems is indeed not an easy task, because their proficiency cannot ensure faithful, expressive and elegant translation. But it's not so hard to overcome the difficulties in word choice with the help of dictionaries. Their translation showed that they could make the best use of dictionaries to seek the right word in translation.

Lecture 7: Writing conference. This lecture is composed of four steps. 1) Provide students with specific living examples in students' writing and analyze their problems of inappropriate choice of words and Chinglish in writing. Teacher should draw students' awareness to the fact that using dictionaries properly can help to avoid those problems and thus improve their writing. 2) Assisted by dictionaries, the teacher, together with students, revise one piece of writing written by a student, to learn how to polish an article. Draw students' attention to the following perspectives: Chinglish, improper collocation and mistakes in part of speech. 3) Students work in groups of four, discuss and revise the articles delivered to their group written by their classmates. 4) Each group presents their product of revision. 
Working in groups to revise their own writing with the help of dictionaries can improve students' both awareness and ability of using language appropriately.

Lecture 8: Using semantic information in dictionaries. In forms of teacher's explanation and illustration, this lecture elaborates the importance of using semantic information in dictionaries in the following three aspects: 1) Definitions of an entry word include its basic meaning, extended meaning, figurative meaning, etc.. Figurative meaning contains its cultural implication which is significant to the understanding and application of language. Besides, dictionaries also provide synonyms, antonyms and derivations of words, which are helpful to improve the diversity and flexibility in writing. Some additional information such as labels for part of speech, grammar, style, etc. is also useful in students' writing. 2) Examples in an entry can specifically reflect its usage patterns, enhancing the learners to express their ideas correctly and properly. However, learners should not rely on only one dictionary. Sometimes they need to consult more than one dictionary to get satisfactory examples. 3) Fixed collocation of words is a typical reflection of English mode of thinking. By learning fixed collocations, students can create more native-like expressions in their writing.

Lecture 9: English writing with the help of dictionaries. Ask students to write an article of 200 words entitled Should Smoking Be Banned. Design three pre-writing activities, namely word tree, words differentiation and filling in proper connectives for an article. Students are required to complete these tasks in forms of group collaboration. During writing, students should use dictionaries to make sure that they can choose the right words, compose correct and proper sentences and argue in logical order.

\section{POST-TRAINING INTERVIEW}

\section{A. Subjects and Instrument}

One week after the training, we conducted a half-structured interview. 20 students were randomly selected from the 80 students who received dictionary use strategy training. They commented on their dictionary use, explained reasons for selecting a certain strategy. A tape recorder was used to record the interview. All the tapes were transcribed and analyzed immediately after the interview was finished.

\section{B. Results and Discussion}

The training had great influence on students' English learning.

Before the training, when they came across a new word in reading, students could only guess its meaning from the context. After the training, they have learned to observe its usage and figure out its collocation and usage pattern from its context.

Distinguishing between synonyms has been a tough problem in students' English learning. But in the training, the teacher assigned synonyms for students to distinguish in the first place, and then asked them to distinguish synonyms they found in reading materials they chose for themselves in extra-class study. In this way, students' initiative was greatly improved. In addition, in the later part of the training, the focus was shifted from synonym distinction to the translation and composition of poems and proses, namely from word level up to the passage level. Students' ability has been further improved.

Dictionaries play a positive and active role in translating and writing, which involve the choice among different words, since they are language producing processes. Therefore, how to choose the most appropriate word to convey feelings and meanings becomes the focus of the later part of the training. By presenting how to translate poems and proses, the teacher led students to seek the right words with the help of dictionaries. After a series of training, students can properly translate some ancient poems and contemporary proses on their own. Starting from synonym distinction, the expected purpose of the training, that is, holistically improve students' ability to use language, has been achieved.

\section{THE TEACHER's EXPERIENCE IN THE TRAINING}

\section{A. The Influence of the Training on the Teacher}

Teacher's working focus has been shifted due to the influence of dictionary on students learning as well as the rearrangement of class time. Before teaching dictionary use strategy, teachers spent much time consulting dictionaries for the explanations and usages of words during the preparation of the lessons. Teaching efficiency was poor and students needed to be supervised and compelled by the teacher to finish their homework. However, after the teaching of dictionary use strategies, teacher's time on preparation for lessons has been spent in designing activities to improve students' independent study. When preparing for a lesson, the teacher will firstly think about which words can be learned by students on their own, and which words need to be learned together with teacher and other students through discussion. The teacher began to attach much importance to students' observation of illustrative sentences, let students find out the usage of words by themselves, so as to raise their language awareness.

It is not the teacher who speaks for the whole class. Sometimes a student's accurate understanding of a word in a certain context brings the house down. Using dictionaries makes the class full of happiness resulting from the discovery of language rules and the creative use of target language. What the teacher does after class is not urge students to review lessons, but deal with students' eagerness for learning. Though teacher's amount of work was not reduced, the later working state gives the teacher more career satisfaction and makes teaching more effective. 
The teacher plays the leading role in the training. She is the one who designs and implements the teaching of dictionary use strategies. In the processes of preparing for the lesson, having class and discussing with students, along with students' formation of good learning habit and improvement of learning efficiency, the teacher has got her own professional development.

\section{B. Some Common Problems Occurred in the Training and Their Solutions}

Students hold different dictionaries in class, which may bring about some difficulty in the dictionary using activities. For the same entry word, they may find out different explanations and illustrative sentences. It is undoubtedly desirable if students are required to use the same kind of dictionaries. But teachers can draw students' attention to the explanation, collocation and usage of words, ask them to compare the explanations since they may be different in different dictionaries. The different dictionaries can enrich illustrative sentences for the students.

At the beginning, learning may be slow in class. There may not be too many activities in class since the main purpose is to teach strategies to students. Homework concerning dictionary use may be assigned to students, with detailed requirement being specifically stated. As students' ability improves, they will use dictionaries more and more skillfully.

It is desirable that the time spent on using dictionaries be limited to 10 to 20 minutes. Too long a time may distract students' attention, and hence reduce class efficiency. The best effect can be achieved if dynamic strategies of teaching and learning vocabulary can be used.

\section{CONCLUSION}

It is necessary for teachers to instruct effective strategies of using dictionary. This research suggests that ownership of dictionary does not necessarily mean the effective use of dictionary. Teachers' instruction with specific purpose and practical plan, plays an important role in students' dictionary use. Before the training, students merely used dictionary as a tool for translation. They depended more on Chinese explanations than the English ones. They paid little attention to the collocation, derivation and illustrative sentences in the entry. In the one-term training, students experienced various functions of dictionaries through the completion of dictionary using tasks designed by the teacher, and gradually achieved dictionary use strategies under teacher's guidance. Now, when they come across new words, they have their own judgment as to which words only need guessing based on their contexts, which words need to be looked up in the dictionary, which need to be studied in detail and which need not. Meanwhile, students have learned to pay close attention to such information in the entry as pronunciation, illustration, derivation and collocation.

Teachers should pay enough attention to the significance of dictionary use strategies, which is one of the cognitive strategies. In their teaching practice, teachers should fully recognize the current situation that students are lack of systematic knowledge and strategies of using dictionaries, and make plans to train them in this aspect accordingly. Dictionary is the most successful and important book about language, in which the explanations and illustrations provide contexts for learners of non-English natives to determine the meaning and conventional usage of words, and offer further distinction of meanings so as to tell learners how to speak and write in that language. Therefore, teachers should strengthen their instruction of how to learn illustrations in dictionaries to students, so that students can use such a resource effectively.

It is feasible to integrate the teaching of dictionary use strategy into Basic English class. This research proves that dictionary has positive influence on various aspects of English learning, and that it is feasible to integrate the teaching of dictionary use strategy into Basic English class because it improves the traditional approach of teaching vocabulary. By using dictionaries, students' initiative of learning has been raised and their interest and confidence have been stirred. Teaching approaches have been enriched and refreshed and classroom atmosphere has become livelier.

The cultivation of students' dictionary use strategy is a work that is done once and for all. By scientifically integrate dictionary use strategy teaching into Basic English teaching and make it in coherence with the whole process of English major teaching, the quality of teaching can be improved to a large extent, and the existing teaching structure and pattern of Basic English can be optimized.

\section{REFERENCES}

[1] Ali, H. I.H. (2012). Monolingual dictionary use in an EFL context. English Language Teaching, 7, 16-24.

[2] Atkins, B. \&Varantola, K. (1998). Language learners using dictionaries: the final report on the EURALEX/AILA research project on dictionary use. In Atkins B. (Eds.) Using dictionaries: studies of dictionary use by language learners and translators. Tubingen: Max Niemeyer Verlag.

[3] Béjoint, H. (1981). The foreign students' use of monolingual English dictionaries: a study of language needs and reference skills. Applied linguistics, 2, 207-222.

[4] Béjoint, H. (1994). Modern Lexicography: An Introduction. Oxford: Oxford University Press.

[5] Chen Min \& Li Shoujing. (2009). A survey of Chinese college students' dictionary use in vocabulary learning and its enlightenment. Journal of Changchun University of Science and Technology, 2, 307-309.

[6] Chen Yuzhen. (2007). A survey and analysis of college English majors' dictionary use. Lexicographical Studies, 2, 120-130.

[7] Chen Yuzhen. (2008). Current approaches to dictionary use training to English majors - the second study on dictionary use training. Lexicographical Studies, 3, 124-134.

[8] Cubillo, M. (2002). Dictionary use and dictionary needs of ESP student: an experimental approach. International Journal of 
Lexicography, 1, 135-146.

[9] Huang, S. \& Eslami, Z. (2013). The use of dictionary and contextual guessing strategies for vocabulary learning by advanced English-language learners. English Language and Literature Studies, 3, 1-7.

[10] Lang Jianguo \& Li Jin. (2003). A survey of English learning dictionary use. Journal of Beijing International Studies University, 6, 54-63.

[11] Laufer, B. \& Kimmer, M. (1997). Bilingualized dictionaries: how learners really use them. System, 3, 361-369.

[12] Li Hongna. (2007). A Study on the Training of Dictionary Use Strategy in Vocabulary Learning in High School. Dissertation for master's degree submitted to Capital Normal University.

[13] Liu Lin. (2013). A survey of English majors' dictionary use. Reference to Culture and Education, 15, 188-189.

[14] Meng Zhen \& Shao Chenghua. (2005). On guidance to middle school students' dictionary use. Foreign Language Teaching \& Research in Basic Education, 3, 37-39.

[15] O’Malley \& Chamot. (1990). Learning Strategies in Second Language Acquisition, Cambridge: Cambridge University Press.

[16] Shi, G. \& Chen, G. (2007). A survey of English majors' dictionary use. Foreign Languages Research, 1, 66-70.

[17] Wang, Q. \& Chen, Z. (2011). An Innovative Research on High School English Teaching Based on E-dictionary. Shanghai: Shanghai Foreign Language Education Press.

[18] Zhao Wei. (2004). A survey of college non-English majors' dictionary use strategies. Foreign Language World, 2. 29-34.

Lin Liu was born in Yantai, China. She received her MA degree, majoring in foreign linguistics and applied linguistics from Qufu Normal University in 2001. She is now teaching English phonetics and advanced English in University of Jinan, China. Her research interests include language teaching methodologies, teacher education and professional development. 